"SOCIALIZATION \& HUMAN DEVELOPMENT" INTERNATIONAL JOURNAL

\title{
PSYCHOLOGICAL FEATURES OF DIFFERENT ETHNIC GROUPS' MALE REPRESENTATIVES WITH DIFFERENT CULTURAL MODES
}

https://doi.org/10.37096/SHDISJ-20-1.1-0003

\section{Mambetova Arzy \\ ORCID 0000-0001-8586-5078}

\begin{abstract}
The article analyzes the works of domestic and foreign authors on the problem of family values in adolescence and describes the attempt to make a research on psychological features of different ethnic groups' representatives with different cultural modes. It contains theoretical and empirical analysis of psychological features of different ethnic groups' representatives with different social modes on the example of representatives of Ukrainian and Crimean Tatar ethnic groups. The problem of social psychological research of processes of development of integrity of personality is examined in the conditions of modern society. On the basis of assumption about the presence of types of socialization corresponding to the different cultural modes there are described the types of integrity of personality - traditional, modern, postmodern. The creation of psychological portraits of representatives of individual ethnic groups with different social styles allowed to study the above issues in more detail, and the novelty of this study would be an impetus for further in-depth scientific elaboration of this topic. Life within a certain cultural mode in an ethnic group influences the psychological wellbeing of ethnic representatives. Thus, the purpose of the article was to portrait the psychological characteristics of the representatives of the studied ethnic groups. The portraits were composed on the basis of socio-cultural components of psychological wellbeing. The aforementioned study was conducted among 70 young men aged from 18 to 25 years who belonged to Ukrainian and Crimean Tatar ethnic groups (35 people from each group respectively). The study used the next mentioned instruments: Questionnaire "Development of the whole personality in the conditions of modern changes" (Vlasova O.I., Shcherbina V.S.); Riff Psychological Well-Being Scale Technique. The results obtained allowed us to establish a typical distribution of the prevalence of known cultural modes among young men - Ukrainians and Crimean Tatars.
\end{abstract}

Key words: family, family values, personality, family style, different cultural modes, traditionalism, modernism, postmodernism.

\section{Introduction}

Our society is very dynamic, and every day there are some transformations of living conditions, which leads to changes in the value sphere. These changes are reflected in the outlook and features of the organization of life of the population. The development of modern youth is taking place in a multicultural world where people have features of different social systems. In such circumstances, it is very important to study and analyze the values of modern youth (Vakulenko, 2016; Vlasova, 2019; Onyshchenko, 2019).

Today, personality development takes place in a multifaceted society that has a dynamic and complex structure. If previously traditional, industrial (modern) 
and communicative (postmodern) cultural structures coexisted hierarchically, they form a single socialization environment, where there is no uniform interpretation of the norms, values and procedures of legitimation at the institutional level. Under these conditions, mutual understanding between people is achieved at the level of interpersonal communication (Vlasova, Fadieieva, \& Hulenko, 2014; Ananova, Vlasova, Danyliuk, et.al., 2015).

Therefore, we will analyze in more detail the most important thematic achievements of modern domestic and foreign scientists. Researches on the subject of formation of a holistic personality were carried out in different subject areas: (philosophy, psychology, pedagogy, sociology, etc.). In classical psychology, the integrity of the individual is regarded as the umwa and the mechanism of ensuring the psychological, social, and personal maturity of a person (Allport, 1955). This is manifested in the personality's ability to construct identities, self-actualization, and self-realization in academic achievement (Maslow, 1954; Erikson, 1968). Modern developments in positive psychology (Deci, \& Ryan, 2000) trace the tendency to search for the prospect of solving the scientific-methodical problem related to the search for criteria of personality integrity, the potential of the construct of subjective well-being or human happiness. The experience of happiness points to the harmony and unity and coherence of her inner world and living conditions. At the level of human subjective representation, this corresponds to the notion of the integrity of the individual as a system of human being to society.

Modern Ukrainian psychological science has also joined the consideration of this issue. O.I. Vlasova, I.V. Danylyuk, I.V. Ananova, A.S. Hulenko, K.M. Fadieieva, V.L. Shcherbyna and others dedicated their researches to the problem (Ananova, Vlasova, Hulenko, Danyliuk, Fadieieva, Shcherbyna, 2015).

Thus the purpose of the article was to explore the processes of development of integrity of personality is examined in the conditions of modern society and to portrait the psychological characteristics of the representatives of the studied ethnic groups.

\section{Theoretical background}

Psychological well-being as a holistic subjective experience is of great importance to the individual as it is linked to basic human values and needs, as well as to everyday concepts such as happiness, happy life, life satisfaction and self. In this situation, the person places emphasis on the subjective emotional evaluation of the person himself and his own life, as well as aspects of self-actualization and personal growth. Most successfully, these two aspects are synthesized and characterized in the six-component theory of psychological well-being by K. Ryff (Ryff, \& Keyes, 1995; Ryff, \& Singer, 1998).

Particular attention is paid to the selfdetermination theory of R. Ryan and E. Deci (Deci, \& Ryan, 2000) in terms of factors that influence psychological wellbeing. The authors believe that personal well-being is also related to basic psychological needs, namely: the need for autonomy, competence and a positive relationship with others. Autonomy refers to the perception of one's behavior as congruent with intrinsic values and desires of the individual. Autonomy is based on support and lack of control by other people. Competence is the tendency to master your environment and to be effective in it. Under 
the "need to connect with others" is the desire to be close to other people. It develops if a person receives warmth and care from others. Thus, meeting psychological needs that are directly related to the social context increases the level of psychological well-being, otherwise the level of psychological wellbeing decreases (Ryff, \& Singer, 1998; Vlasova, Fadieieva, \& Hulenko, 2014).

Ethnicity and identity play an important role in the manifestation of psychological well-being. It is ethnicity that is associated with the inner world of man. Any other personality trait associated with its identification is usually functional in the social sense and is more likely to change.

Ethnic identity is based on a common cultural knowledge, cultural experience that is common to the group; then, of course, an ethnic group has the right to expect from each person behavior that is adequate for his or her role as a member of that group. And in this case, merely attributing such a role to the individual seems clearly insufficient. But it should also be borne in mind that the cultural foundations (cultural knowledge) on which intra-ethnic relations are based are much more complex and less structured than those on which interethnic relations are built (Danyliuk, Kozytska, \& Shykovets, 2018).

Specification of ethnic identity is largely determined not only by its subjective but also by social modality. Thus, under the conditions of the multiethnic structure of a society, the distribution of ethnic groups by their status is not excluded, which in turn makes it possible to display presentational identification (in order to achieve higher status) with a more prestigious ethnic community (while maintaining devotion to one's own ethnic values). This development can be triggered not only by the atmosphere of the micro environment, but also by the state as a whole (Bulatevich, \& Mambetova, 2018).

Moreover, representatives of small ethnic groups are generally characterized by an exacerbation of ethnic consciousness, which under certain conditions is capable of intensification. Hence the growing demands for commitment to shared group values and the strengthening of opposition to one's own communities.

In the context of social change, there is an influence of cultural modes on the peculiarities of the existence of the society (multicultural environment) of the country as a whole and its constituents (ethnic communities) in particular.

Based on this, we should elaborate on the notion of cultural style. It characterizes the historically steady, typical features of the order of constructing and substantive content of normative-value constructs that are inherent in social groups and individuals and are expressed in the material, ideal organizational and symbolic components of their individual and group life in the context of a particular society. Cultural mode is a specific historical phenomenon, inherent in the human community and is characterized by the principles of construction, ways of exchanging activities, material (technological) basis, the type of values and norms, socio-historical and spatio-temporal determination. The monomodal and multimodal societies are distinguished. Ukraine belongs to the latter. Depending on the methods of social production, cultural studies distinguish typical cultural modes, such as: archaic, traditional, modern and 
"SOCIALIZATION \& HUMAN DEVELOPMENT" INTERNATIONAL JOURNAL

postmodern (Vlasova, Fadieieva, \& Hulenko, 2014).

The culture in society is represented by a certain set of values and norms, historically formed by the practices of their realization. Therefore, the multidimensionality of socialization space can be explored through the multidimensionality of the cultural constructs or modes present in it. Cultural modes do not exist in themselves or affect some individuals, but on the contrary, the individual adapts them for himself, and carries out certain activities for them as conditions of his own being (Shcherbyna, 2014).

According to the traditional cultural mode values are considered independently of man and society, and given by an external authority (God, Nature), the imperative of life, which the individual may or may not respond in real life.

The modern cultural mode considers values as those created in the process of joint purposeful activity of people and having imperative, urgent value only in the context of achieving the common goal and efficiency of life of the group and the individual.

Postmodern cultural mode involves understanding of values as a kind of tools for game that is being undertaken in order to enjoy interaction in different areas of life. In this case, they are relative, contextual, state-oriented and communication processes.

\section{Methodology}

Ukraine is a multi-ethnic country. In the last six years, after the occupation of Crimea, more and more internally displaced persons have appeared in mainland Ukraine, namely the Crimean Tatars. The study of the socio-cultural context will make it possible to understand exactly what imprint it imposes on the psychological characteristics of representatives of different ethnicities. In the socio-cultural environment of different ethnic groups, the same social structures function, but their correlation in the environment of each ethnic group and their influence on the systems of ethnic factors and characteristics are unique. Thus, the creation of psychological portraits of representatives of individual ethnic groups with different social styles will allow to study the above issues in more detail, and the novelty of this study will be an impetus for further in-depth scientific elaboration of this topic.

Life within a certain cultural mode in an ethnic group influences the psychological well-being of ethnic representatives. Thus, the purpose of the article is to portrait the psychological characteristics of the representatives of the studied ethnic groups. The portraits should be composed on the basis of socio-cultural components of psychological well-being.

The aforementioned study was conducted among 70 young men aged from 18 to 25 years who belonged to Ukrainian and Crimean Tatar ethnic groups (35 people from each group respectively).

The study used the next mentioned instruments:

- Questionnaire "Development of the whole personality in the conditions of modern changes" (Vlasova O.I., Shcherbina V.S.) (Vlasova et. al., 2014; Shcherbyna, 2014).

The test measures existential fullness as it is subjectively felt by the subject. The Existence Scale consists of four subscales according to basic anthropological personality abilities that are necessary to 
identify meaning: SD (self-distancing), ST (self-transcendence), F (freedom), V (responsibility). Here, self-transcendence and self-distancing constitute the personal factor or personal preconditions of being full, while freedom and responsibility are the existential factor or fullness due to the possibilities of the situation. The overall indicator for the test indicates the degree of completeness that is subjectively experienced by the person. The ratio of these scales determines belonging to one of three cultural modes: traditional, modern or postmodern. Defining this affiliation is one of the key objectives of our study and the reason for using this method.

- Ryff Psychological WellBeing Scale Technique (Ryff, \& Keyes, 1995).

The psychological well-being scale technique by $\mathrm{K}$. Ryff consists of the following scales: positive relationships with others, autonomy, environmental management, personal growth, life goals and self-acceptance. The scale of positive relationships with others characterizes the personality's ability to create and maintain trusting and open relationships with people. The autonomy scale characterizes the individual as independent and independent, capable of making decisions independently. The environment management scale describes a person's ability to influence the environment and control his or her own life. The scale of personal growth characterizes the individual as having a sense of constant self-development, realization of one's own potential. The Life Purpose Scale characterizes a person who has life goals and a meaningful existence. The selfacceptance scale characterizes the individual as accepting of himself, knows his strengths and weaknesses, and is positive about himself.

The results obtained allowed us to establish a typical distribution of the prevalence of known cultural modes among young men - Ukrainians and Crimean Tatars.

\section{Results}

Thus, traditional (50\%) and postmodern $(40 \%)$ cultural modes are dominant among Ukrainian young men (see Fig. 1). In theory, such a combination can create internal conflict in the society, since traditional and postmodern modes are fundamentally contradictory in the interpretation of values. Accordingly, the individual, adapting them for himself as a condition of his own being, is forced to carry out simultaneously two activities that contradict each other or are being directed against each other. We were able to verify this assumption later, after analyzing the psychological characteristics of the Ukrainian youths' social behaviors. 


\section{Distribution of cultural modes among Ukrainian young men}

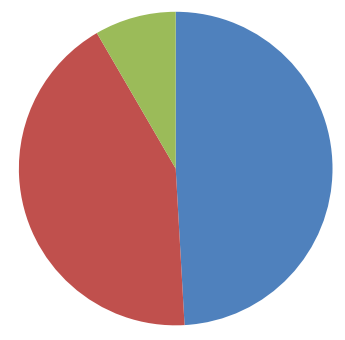

Traditional 50\%

Postmodern $40 \%$

Modern $10 \%$

Fig. 1 Distribution of cultural modes among Ukrainian young men

At the same time, the modern mode common points of contact with the $(60 \%)$ is dominant among Crimean Tatar approaches of traditional and postmodern youung men, The modern mode is in modes. This fact creates a favorable harmony with the traditional $(25 \%)$ and environment for cultural public dialogue. postmodern (15\%) modes (see Fig. 2). We were able to verify this assumption Theoretically, such a combination can later, after analyzing the psychological create a rather favorable situation in characteristics of the Ukrainian youths' society, because the approach to the values, social behaviors. promoted by the modern way, finds

\section{Distribution of cultural modes among Crimean Tatar young men}

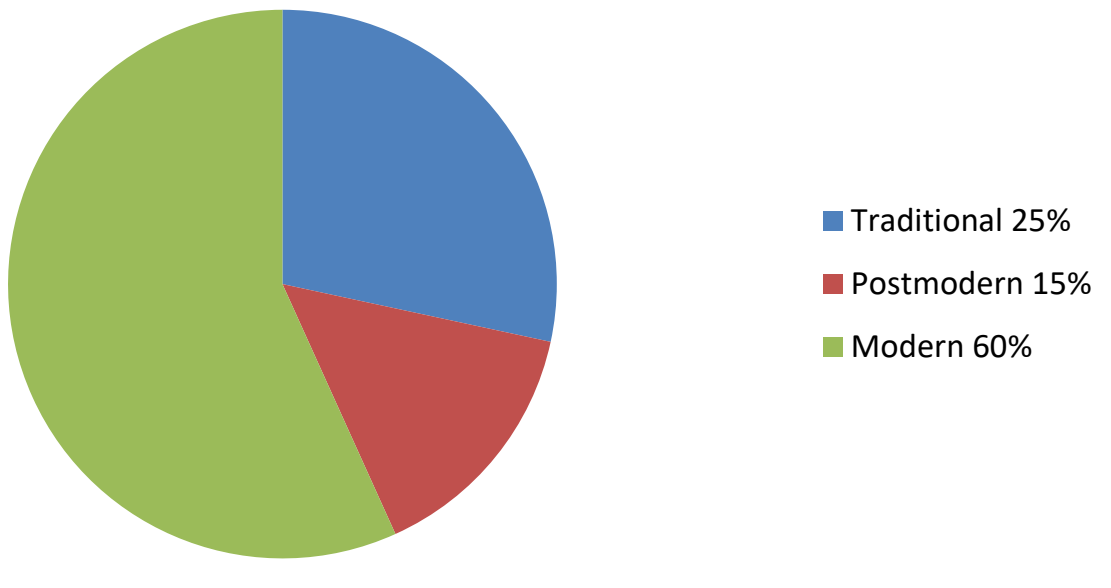

Fig. 2 Distribution of cultural modes among Crimean Tatar young men.

We were also able to determine how the factors of psychological well-being (using the Riff Psychological Well-Being Scale) are reflected in the outlook of the studied youths - Ukrainians and Crimean Tatars, and how they exert their influence.
Thus, the Ukrainian young men are characterized by: average level of positive relations with others, maximum high level of autonomy, rather low level of environmental management, medium level of personal growth, low level of goals in 
"SOCIALIZATION \& HUMAN DEVELOPMENT" INTERNATIONAL JOURNAL

life (according to respondents, this is life in the country ), medium level of selfinfluenced by social and political factors of acceptance (see Fig. 3).

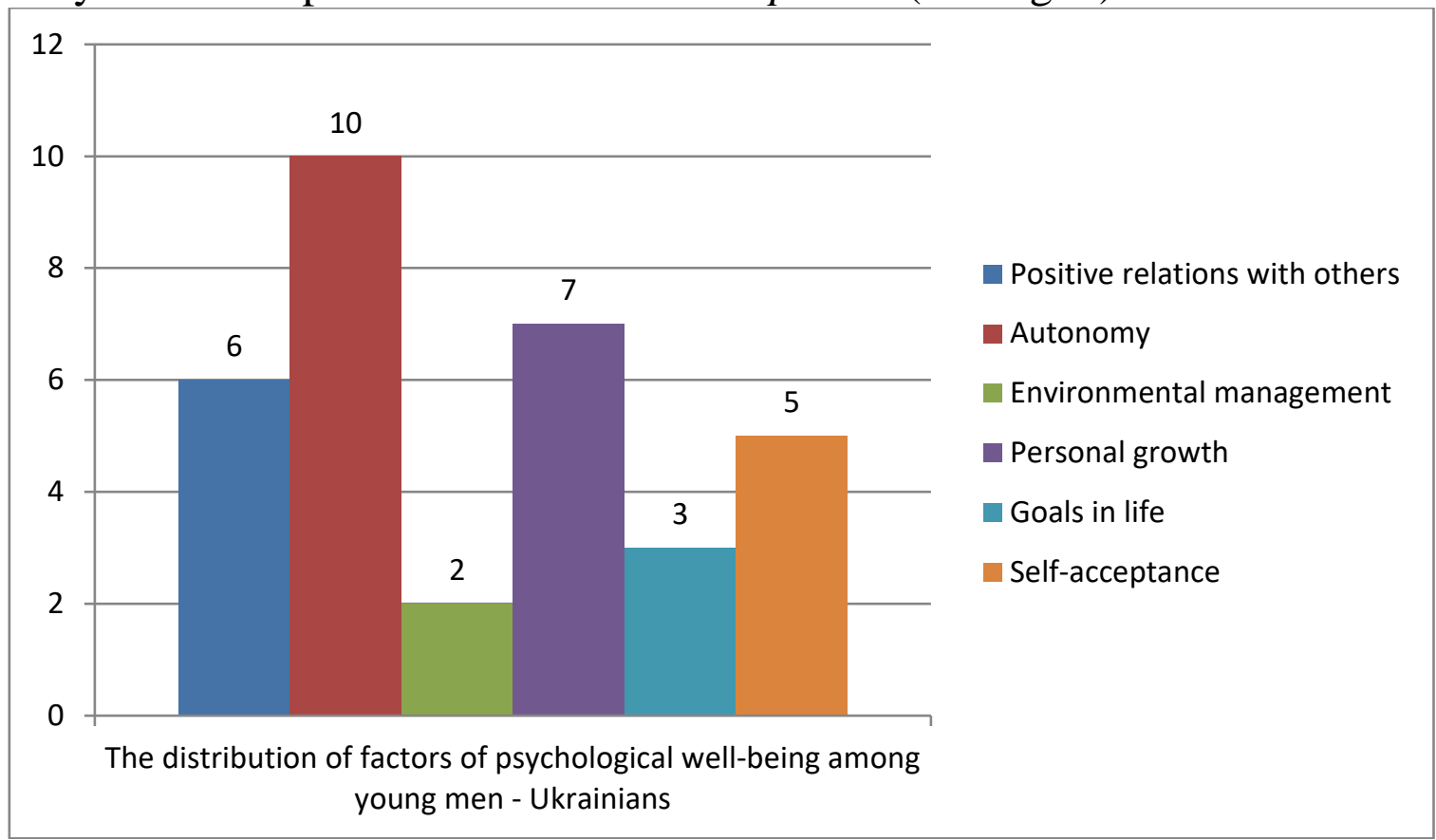

Fig. 3. The distribution of factors of psychological well-being among young men - Ukrainians.

The Crimean Tatar young men are personal growth, and a low level of goals characterized by a rather high level of in life (according to respondents, this is positive relations with others, an average influenced by social and political factors in level of autonomy, a maximum level of the country), medium level of selfenvironmental management, a high level of acceptance (see Fig. 4).

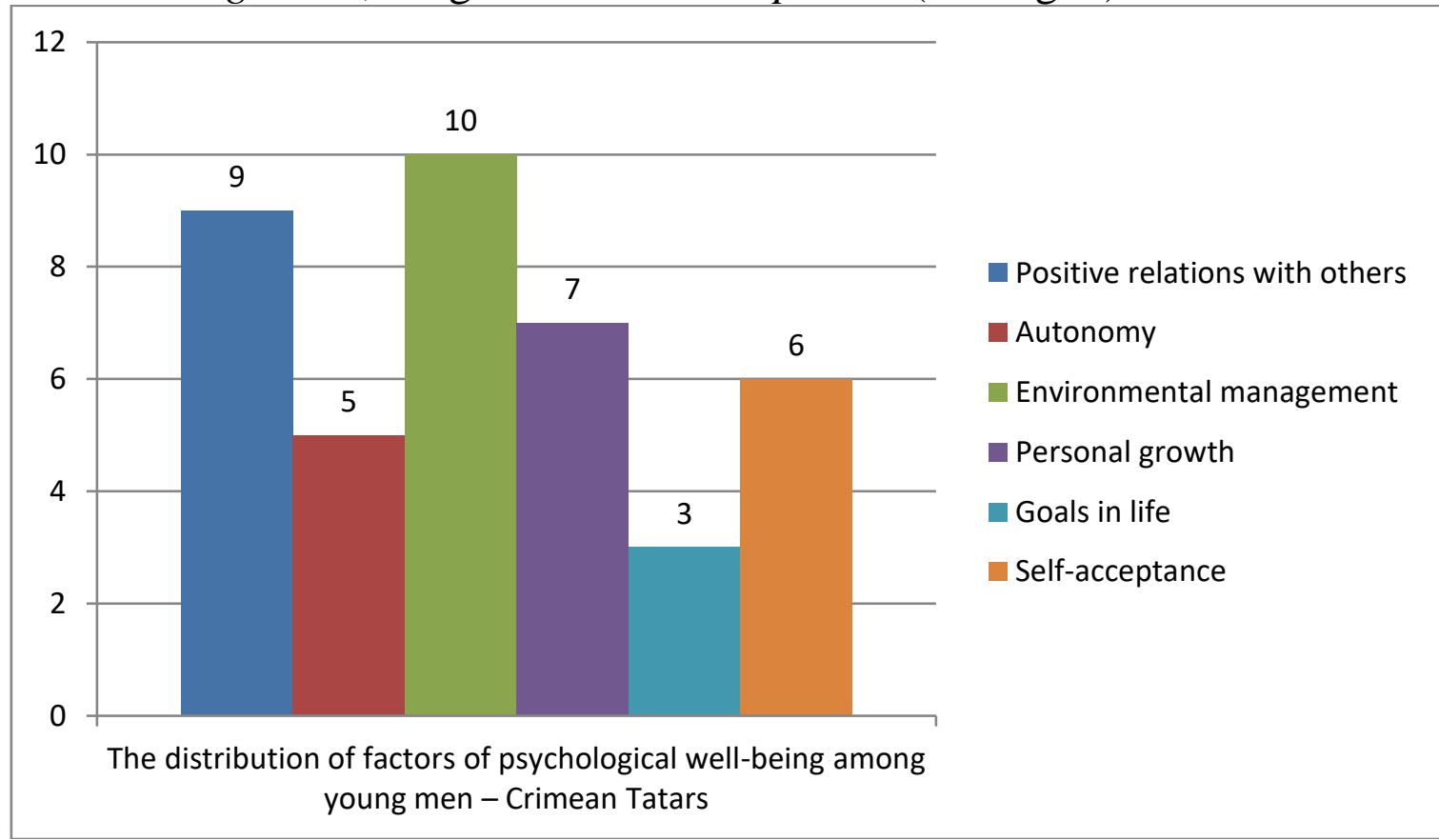

Fig. 4. The distribution of factors of psychological well-being among young men - Crimean Tatars In order to analyze the psychological conducted a correlation study of the peculiarities of Ukrainian and Crimean connection between cultural styles (the Tatar young men social behaviors, we questionnaire "Development of a holistic 
"SOCIALIZATION \& HUMAN DEVELOPMENT" INTERNATIONAL JOURNAL

personality in the context of modern changes" (Vlasova O. I., Shcherbina V. S.)) with psychological factors well-being (the Ryff Psychological Well-Being Scale technique).

Thus, we obtained a portrait of the psychological characteristics of the studied Ukrainian young men, who chose the dominant cultural modes in the Ukrainian community (see Table 1). This analysis has allowed us to develop a working out of assumptions about the personal psychological characteristics of persons belonging to certain cultural modes.

Consequently, young men Ukrainians who chose the traditional cultural mode have an average level of positive relations with others (the average correlation strength) (the result corresponds to the distribution of factors of psychological well-being among Ukrainian young men (Fig. 3)); a low level of autonomy (inverse correlation) (the result does not correspond to the distribution of factors of psychological well-being among Ukrainian young men (Fig. 3), where the level of autonomy was as high as possible hence the choice of values of the traditional way of young men - Ukrainians causes conflict with their autonomy); a low level of environmental management (inverse correlation) (the result corresponds to the distribution of factors of psychological well-being among young men - Ukrainians (Fig. 3)); a low level of personal growth (inverse correlation) (the result does not correspond to the distribution of factors of psychological well-being among young men - Ukrainians (Fig. 3), where the level of personal growth was average); an average level of goals in life (average strength of correlation) (the result does not correspond to the distribution of factors of psychological well-being among young men - in disputed one (Fig. 3), where the goal in life was average); an average level of self-acceptance (average correlation power) (the result corresponds to the distribution factors psyhological wellbeing among Ukrainian young men (Fig. 3)).

Young men - Ukrainians who chose a postmodern cultural mode, are characterized by an average level of positive relations with others (average correlation strength) (the result corresponds to the distribution of factors of psychological well-being among young men - Ukrainians (Fig. 3)); a high level of autonomy (strong correlation) (the result corresponds to the distribution of factors of psychological well-being among Ukrainian youths (Fig. 3); a low level of environmental management (inverse correlation) (the result corresponds to the distribution of factors of psychological well-being among Ukrainian youths (Fig. 3)); an average level of personal growth (average strength of correlation) (the result corresponds to the distribution of factors of psychological well-being among young men - Ukrainians (Fig. 3)); an average level of goalse in life (average strength of correlation) (the result does not correspond to the distribution of factors of psychological well-being among Ukrainian youth (Fig. 3), where the goal level in life was low); a high level of self-acceptance (strong correlation) (the result does not correspond to the distribution of factors of psychological well-being among young men - Ukrainians (Fig. 3), where the level of self-acceptance was average). 
"SOCIALIZATION \& HUMAN DEVELOPMENT" INTERNATIONAL JOURNAL

Table 1

Correlation of cultural modes (questionnaire "Development of holistic personality in the conditions of modern changes" (Vlasova O.I., Shcherbina V.S.)) with factors of psychological well-being (the method "Ryff psychological well-being scale ") for young men - Ukrainians

\begin{tabular}{|c|c|c|c|}
\hline Cultural modes & Psychological well-being factors (Riff) & Correlation coefficient & p-value \\
\hline \multirow{6}{*}{ Traditional } & Positive relations with others & 0,68 & 0,001 \\
\hline & Autonomy & $-0,9$ & 0,001 \\
\hline & Environmental management & $-0,9$ & 0,001 \\
\hline & Personal growth & $-0,9$ & 0,001 \\
\hline & Goals in life & 0,7 & 0,001 \\
\hline & Self-acceptance & 0,6 & 0,001 \\
\hline \multirow[t]{6}{*}{ Postmodernism } & Positive relations with others & 0,6 & 0,001 \\
\hline & Autonomy & 0,9 & 0,001 \\
\hline & Environmental management & $-0,9$ & 0,001 \\
\hline & Personal growth & 0,6 & 0,001 \\
\hline & Goals in life & 0,6 & 0,001 \\
\hline & Self-acceptance & 0,9 & 0,001 \\
\hline
\end{tabular}

We also described a portrait of the psychological traits of the investigated Crimean Tatar young men who chose the dominant cultural modes in the Crimean Tatar community (see Table 2). This analysis has allowed us to develop a working out of assumptions about the personal psychological characteristics of persons belonging to certain cultural modes.

Thus, Crimean Tatar young men who have chosen a modern cultural style have a high level of positive relations with others (strong correlation) (the result corresponds to the distribution of factors of psychological well-being among Crimean youths (Fig. 4)); an average level of autonomy (average strength of correlation) (the result corresponds to the distribution of factors of psychological well-being among the young men - Crimean Tatars (Fig. 4)); a low level of environmental management (inverse correlation) (the result does not correspond to the distribution of factors of psychological well-being among the youth - Crimean Tatars (Fig. 4), where the level of environmental management was high); an average level of personal growth (average strength of correlation) (the result corresponds to the distribution of factors of psychological well-being among the youth - Crimean Tatars (Fig. 4)); a high level of goals in life (strong correlation) (the result does not correspond to the distribution of factors of psychological well-being among the youth - Crimean Tatars (Fig. 4), where the level of purpose in life was average); a low level of self-acceptance (inverse 
"SOCIALIZATION \& HUMAN DEVELOPMENT" INTERNATIONAL JOURNAL

correlation) (the result does not correspond to the distribution of factors of psychological well-being among the young men - Crimean Tatars (Fig. 4), where the level of self-acceptance was average).

Table 2

Correlation of cultural modes (questionnaire "Development of holistic personality in the conditions of modern changes" (Vlasova O.I., Shcherbina V.S.)) with factors of psychological well-being (the method "Ryff psychological well-being scale") for young men - Crimean Tatars

Cultural modes $\quad$ Psychological well-being factors (Ryff) Correlation coefficient $p$-value

\begin{tabular}{|l|l|r|r|}
\hline \multirow{3}{*}{ Modernism } & Positive relations with others & 0,9 & 0,001 \\
\cline { 2 - 4 } & Autonomy & 0,7 & 0,001 \\
\cline { 2 - 4 } & Environmental management & 0,9 & 0,001 \\
\cline { 2 - 4 } & Personal growth & 0,6 & 0,001 \\
& Goals in life & 0,9 & 0,001 \\
\hline & Self-acceptance & $-0,9$ & 0,001 \\
\hline
\end{tabular}

The results obtained show that the peculiarities of the psychological wellbeing factors inherent in cultural modes do not always correspond to the peculiarities of the psychological well-being factors inherent in individuals or groups. In view of this, it is important to further explore the interplay of values between ethnic groups and cultural modes. The obvious fact is that an individual can change their own value code by accepting the value code of a particular cultural mode. The same processes can be a characteristic of ethnic groups. A detailed study of these and the possibility of further adjustment through educational and development strategies is the goal of our further research.

\section{Discussion}

The process of conducting our research was divided into two directions:

1. Conducting an empirical study on the prevalence of cultural modes among young male members of the Ukrainian and Crimean Tatar ethnic groups.
2. Conducting an empirical study on the correlation of cultural modes with factors of psychological well-being for young men - Ukrainians and Crimean Tatars.

In this cross-cultural approach, in our opinion, the uniqueness of this study is in comparison with the experience of other researchers already existing (Shcherbyna, 2014; Causadias, Vitriol, \& Atkin, 2018; Baban, 2018; Yang, Liang, Quan, Jiang, Yu, \& Zheng, 2019).

The study was conducted in several stages. At the organizational stage, theoretical information concerning the issue of cultural styles and well-being factors for different ethnic groups was elaborated. In the second stage, empirical research was conducted using standardized techniques. The next stage was the processing and interpretation of the results.

In addition, there are limitations to the results obtained. Thus, the study hypothesis was tested only on young male representatives of Ukrainian and Crimean 
Tatar ethnic groups. However, it is also promising to study the situation in ethnic groups in general. This study opens up the potential for further scientific research and highlights the relevance of the chosen direction of scientific research.

\section{Conclusion}

Theoretical facts indicate that the socio-cultural context (cultural attitudes and belonging to ethnic communities) influences the representatives of the contemporary cultural environment, which is reflected in certain features of the psychological portrait of the individual. In order to study the peculiarities of these phenomena empirically, the authors investigated the psychological peculiarities of social ways in the representatives of the Ukrainian and Crimean Tatar ethnic groups in the contemporary multicultural environment of Ukraine.

The results obtained prove the need for further research in the chosen field.

We have found the expediency of finding strong positive factors that can be used to create tools for positively influencing young people in order to set them up for successful activities, to preserve their own ethno-cultural values in the conditions of adaptation to the challenges of modern society.

This issue is currently relevant because ethnocultural values are the important set of concepts, attitudes, feelings and thinking that give a person an intuitive or conscious incentive to act in order to achieve, preserve or restore the benefits and patterns of interaction envisaged by these values. cultural identity code.

This will greatly increase the efficiency of professional activity and will guarantee the development of a positive identity and the establishment of positive social interaction and re-socialization.

Acknowledgments. The study did not receive a grant from any financial agency in state, commercials or the nonprofit sector.

\section{References}

Allport G.W. (1955). Becoming: Basic Considerations for a Psychology of Personality. New Haven: Yale University Press.

Ananova I. V., Vlasova O. I., Hulenko A. S., Danyliuk I. V., Fadieieva K. - M., Shcherbyna V. L. (2015) The types of personal integrity of the modern Ukrainian multicultural society Socio-economic sciences and challenges of modern technology and planetary communication: International Conference on ICT Management for Global Competitiveness and Economic Growth in Emerging Economies ICTM 2015 : http://papers.ssrn.com Retrieved from URL: http://papers.ssrn.com/sol3/cf_dev/ AbsByAuth.cfm?per_id=2469326 [in Ukraine].

Banban D. (2018). Harmony in diversity: an empirical study of harmonious co-existence in the multi-ethnic culture of Qinghai. International Journal of Anthropology and Ethnology (2018) 2:1. https://doi.org/10.1186/s41257-0180010-6

Bulatevich N., Mambetova A. (2018). Psychological peculiarities of parenthood apprehensions of Ukrainians and Crimean Tartars. International Journal of Education \& Development, 1, 13 - 24 .

Causadias, J. M., Vitriol, J. A., \& Atkin, A. L. (2018). Do we overemphasize the 
"SOCIALIZATION \& HUMAN DEVELOPMENT" INTERNATIONAL JOURNAL

role of culture in the behavior of racial/ethnic minorities? Evidence of a cultural (mis)attribution bias in American psychology. American Psychologist, $\quad 73(3), \quad 243-$ 255. https://doi.org/10.1037/amp000 0099

Danyliuk I.V., Kozytska I.V. \& Shykovets S.O. (2018). The cultural syndrome "Individualism - collectivism"and its psychological peculiarities including well-being of regional communities' representatives in Ukraine. Scientific journal "Fundamental and applied research in practice of leading scientific schools", 30, 6, $55-61$.

Deci E., \& Ryan R. (2000). Selfdetenrrination theory and the facilitation of intrinsic motivation, social development, and well-being. American Psychology. Vol. 55 (1). P. 68-78.

Erikson E. (1968). Identity: Youth and Crisis. New York: Norton.

Maslow A. (1954). Motivation and Personality. NY: Harper.

Onyshchenko V. (2019). Rozvytok tsilovoi spriamovanosti osobystosti pidlitkiv - turystiv [Development of targeting personality of teenagers - tourists]. Visnyk Kyivskoho Natsionalnoho Universytetu imeni Tarasa Shevchenka. Psykholohiia. Issue 1. Vol. 10.

Ryff, C.D., \& Keyes, C.L.M. The structure of psychological well-being revisited // Journal of Personality and Social Psychology, 1995, 69, 719-727

Ryff, C.D., \& Singer, B. Human health: new directions for the next millennium // Psychological Inquiry, 1998, 9, 69-85.
Shcherbyna V. L. (2014) Tsilisnist osobystosti V umovakh bahatoukladnoho suspilstva [The integrity of the individual in a mixed society] «Aktualni problemy sotsiolohii, psykholohii, pedahohiky» Zbirnyk naukovykh prats. - K.: Lohos - "Actual problems of sociology, psychology, pedagogy" Collected Works. - Ed.1 (22) $K$.. Logos, 1 (22), 165-172 [in Ukraine].

Shykovets S.O., Mambetova A.A. (2018). Psychological features of the representatives' identity in the regional communitiesof Ukraine and Poland. Naukovyi Visnyk Khersonskoho Derzhavnoho Universytetu. Psykholohiia Scientific Bulletin of Kherson State University. Psychology, 3, 1, 142 148

Vakulenko O. (2016) Onovlennia identytetiv: uproblemnennia sotsialno-psykholohichnoho dyskursu [Upgrade of identificators: problematization of sociopsychological discourse]. Psykholohiia i suspilstvo., pp. 105 114.

Vlasova O. I., Fadieieva K.-M. O., Hulenko A. S. (2014) Psykholohichnyi konstrukt tsilisnosti osobystosti $\mathrm{v}$ konteksti metodolohii filosofii ekzystentsializmu ta ekzystentsiinoi psykholohii [Construct psychological integrity of the individual in the context of the methodology of the philosophy of existentialism and existential psychology] fund-issledintern.esrae.ru Retrieved from URL: fund-issled-intern.esrae.ru/5-60 [in Ukraine]. 
"SOCIALIZATION \& HUMAN DEVELOPMENT" INTERNATIONAL JOURNAL

Vlasova O.I. (2019). Influence of internet dependency on young people selfactualization. Socialization \& Human Development: International Scientific Journal,1, 1, 5-12.

Yang Y., Liang F., Quan F., Jiang G., Yu K., \& Zheng Y. (2019). The
Importance of Ethnicity: Developing a Measure of Minority Ethnic Value and Value-Expressive Behavior Among Chinese Ethnic Minorities. Front. Psychol., 19. https://doi.org/10.3389/fpsyg.2019.0 $\underline{2603}$ 